
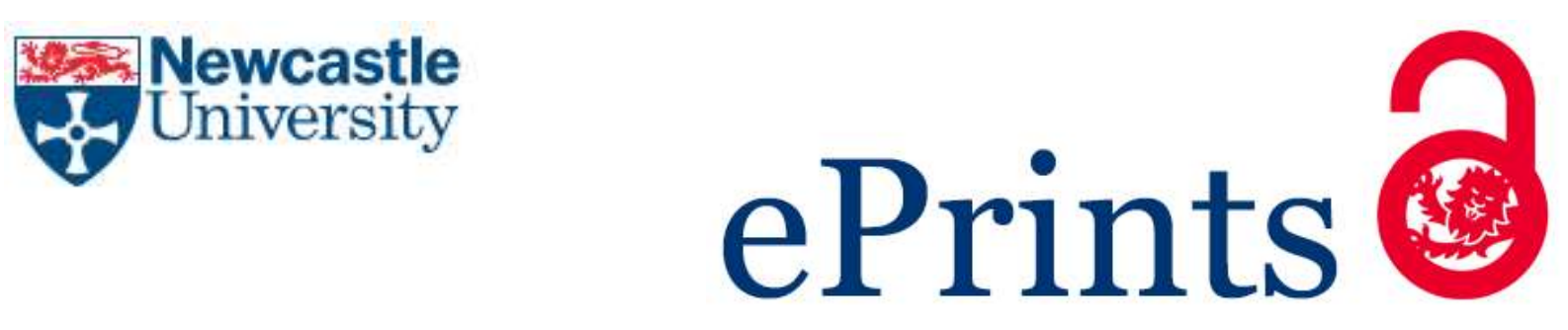

Durham J, Touger-Decker R, Nixdorf DR, Rigassio-Radler D, Moynihan P. Orofacial pain and nutrition: a forgotten relationship?. Journal of Oral Rehabilitation 2015, 42(1), 75-80.

\title{
Copyright:
}

(C)2015 by SAGE Publications

This is the peer reviewed version of the following article: Durham J, Touger-Decker R, Nixdorf DR, Rigassio-Radler D, Moynihan P. Oro-facial pain and nutrition: a forgotten relationship?. Journal of Oral Rehabilitation 2015, 42(1), 75-80., which has been published in final form at http://dx.doi.org/10.1111/joor.12226 This article may be used for non-commercial purposes in accordance with Wiley Terms and Conditions for Self-Archiving.

Date deposited:

$02 / 12 / 2015$

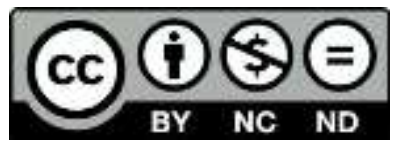

This work is licensed under a

Creative Commons Attribution-NonCommercial-NoDerivatives 4.0 International licence 


\section{Orofacial pain and nutrition: a forgotten relationship?}

Durham $\mathrm{J}^{1^{*}}$, Touger-Decker $\mathrm{R}^{2}$, Nixdorf $\mathrm{DR}^{3}$, Rigassio-Radler $\mathrm{D}^{2}$, Moynihan $\mathrm{P}^{1}$

1 - Institute of Health and Society and Centre for Oral Health Research, Newcastle University, Newcastle, UK.

2 - Rutgers University, School of Health Related Professions, Department of Nutritional Sciences; Rutgers School of Dental Medicine, Department of Diagnostic Sciences. New Jersey. USA

3 - Division of TMD \& Orofacial Pain, School of Dentistry and Department of Neurology, Medical School, University of Minnesota, MN. Research Investigator, HealthPartners Institute for Education and Research, Bloomington, MN. USA.

${ }^{*}$ Corresponding author

Dr J Durham

Level 5

School of Dental Sciences

Framlington Place

Newcastle University

Newcastle-Upon-Tyne

NE2 4BW

UK

Justin.durham@ncl.ac.uk

Tel: +44(0)1912226000

Fax: +44 (0)1912228191

Short title/Running head: Orofacial pain and nutrition

Article category: Commentary

\section{Keywords:}

Facial pain

Diet

Nutrition

Eating 


\section{Humans}

Nutritional status 


\section{Abstract}

Orofacial pain (OFP) is known to exert profound impacts on quality of life including functionally and psychosocially mediated changes in dietary intake and thereby nutrition. This commentary explores the evidence base available on chronic orofacial pain, diet and nutrition and discusses current dietary guidance for individuals with chronic OFP; potential impact of chronic OFP on eating and nutritional status; impact of nutritional status on pathophysiology of chronic OFP; potential role of nutrition in the management of chronic OFP. 


\section{Introduction}

The face and mouth are essential to our everyday lives. They provide us with verbal and non-verbal communicatory capacity, house the majority of our senses, and also allow us to eat and drink to satisfy our nutritional needs. Without adequate nutrient intake, malnutrition and nutrient deficiencies can occur. The oral cavity can be considered a sensitive barometer to the presentation of some of these diseases and therefore oral health care providers have been trained to identify their oral soft tissue clinical presentations.

A body of evidence demonstrates that compromised oral health through either tooth loss and or oral mucosal disease is associated with increased risk of malnutrition (1-7). The potentially bidirectional relationship between chronic orofacial pain (OFP) and diet has, however, received less attention with only a few identifiable papers in the literature $(8-14,14)$.

Many conditions cause pain in the orofacial region (15). A simple way of subclassifying these conditions is into acute (short-term) pain and those with the propensity for pain to be chronic (long-term, $>3$ months) pain (16). Acute OFP conditions may cause short-term changes in dietary intake, but chronic OFP has the potential to exert a more sustained change in dietary intake, which may affect the nutritional status of the individual. Chronic OFP is also more 
likely to have a much greater (psychosocial) impact on individuals (17). The remainder of this commentary will therefore focus on examining the potential impact of chronic OFP on dietary intake and also the role nutrition/nutrients may play in the pathophysiology and management of the common conditions comprising chronic OFP: Temporomandibular Disorders (TMDs), Burning Mouth Syndrome (BMS), Persistent Dentoalveolar Pain disorder (PDAP), and Trigeminal Neuralgia (TN).

The areas of discussion will include reviewing the: current dietary guidance for individuals with chronic OFP; potential impact of chronic OFP on eating and nutritional status; impact of nutritional status on pathophysiology of chronic OFP; and potential role of diet and nutrition in the management of chronic OFP. 


\section{Dietary Guidance for Chronic OFP}

There is a lack of evidence-based dietary guidelines for patients with chronic OFP. The most prudent and pragmatic current advice is to ask patients about their difficulty eating and provide customised dietary guidance based on the challenges the individuals report. Clinicians should try to avoid oversimplifying the advice by for instance describing the need to take a "soft diet" when suffering from Temporomandibular Disorders (18-20). If this oversimplified advice were taken verbatim it may lead to a reduced intake of whole grains, fresh fruits and vegetables or over-processing/cooking of food to soften it, thereby losing nutritional value. Instead of a generic "soft diet" clinicians could consider different methods to help decrease masticatory force but maintain the nutritional value of the food eaten. As an example, "soft bread buns/rolls" require more jaw movement to bite, chew and swallow than foods such as popcorn kernals or chopped tomatoes, all of which have more dietary fibre than most soft forms of bread (21).

Neuropathic / neurovascular and musculoskeletal OFP conditions differ in their clinical management and potential impact on eating. The functional limitation of musculoskeletal conditions may mean that many normal movements required during mastication may cause or exacerbate the pain. This results in a desire to manipulate foods to help address the decreased function. For example, if mouth opening and chewing are difficult because of pain, then clinicians could advise alternative dietary choices or food preparation, such as peeling and cutting fruit, to help allow a balanced diet. 
In neuropathic and neurovascular disorders, the food composition or temperature may exacerbate or play or role in triggering pain. In Trigeminal Neuralgia it may be related to food temperature whereas in Migraine it may be the presence of caffeine or tyramine in foods that trigger the pain.

\section{The impact of chronic OFP on the eating experience and nutritional status}

Pain provides a large proportion of the symptom burden in chronic OFP conditions, but there can also be a concomitant decrease in oral functional ability (22). The decrease in functional ability in TMD can be mediated by fear of movement (23), by the pain itself, or simply through an inability to open one's mouth fully and chew with the same efficacy (22). The physiological and psychological impacts of OFP may also impact on the enjoyment of eating and subsequently quality of life, but there is a dearth of information on this important topic $(17,24,25)$.

The symptom burden of the OFP condition may alter both the choice and the preparation of food, but data on this are limited. Data for patients with TMD, from several decades ago, suggest that meat, apples, and bread might be frequently omitted from the diet (26) and some more recent data have suggested that vegetables and meat might be prepared differently using softer cooking methods (9). Furthermore, research in females with TMD suggested 
that women with higher pain visual analogue scores (VAS) avoided fibre-rich foods more than those with lower VAS scores (13).

If those suffering from chronic OFP that is musculoskeletal in origin choose to exclude foods, such as vegetables, wholegrain foods and dietary fibre then dietary sources of antioxidant vitamins, minerals, and other phytonutrients may be lacking. Emerging evidence suggests that many of these micronutrients have a role in attenuating chronic pain (27) and therefore it is plausible that a reduced intake may compound the OFP. There is, however, a dearth of data on the impact of OFP on the intake of macro and micronutrients and it is not known if dietary alterations over time, lead to changes in nutritional status and subsequent systemic health. 


\section{Impact of nutritional status on pathophysiology of chronic OFP}

Knowledge on the pathophysiology of chronic OFP is improving, but we still lack definitive conclusions. In chronic OFP of an inflammatory origin such as arthrogenous TMD it is plausible that antioxidant status may play a role in the pathophysiology of the condition. Vitamins C, D, and E, soy, carotenoids and an array of dietary flavonoids, have been shown to have antioxidant properties and anti-hyperalgesic effects (28-32). The mechanisms by which antioxidants protect biological systems from free radical damage include the direct scavenging of reactive oxygen species and by the sequestration of free catalytic metal ions, which promote the formation of free radicals, inhibition of nuclear factor kappaB, inhibition of the cyclooxygenase pathway and reduction of lipid perioxidation $(33,34)$. In addition to antioxidant nutrients, the fatty acid profile of the diet may also impact the inflammatory processes associated with OFP. Omega 3 fatty acids (e.g., docosohexanoic acid and eicosapentanoic acid) have an established role in dampening inflammation by reducing the synthesis of pro-inflammatory prostaglandins (PGE2) and leukotriene B4; however the impact on OFP is unknown.

Given that B vitamins such as folic acid have been closely linked to primary BMS $(35-38)$ and alcoholic neuropathy $(39,40)$ it is plausible that select B vitamins (e.g., folic acid, vitamin B12) may play a role in neuropathic OFP conditions' development, persistence, or management. There is also some preliminary evidence that micronutrient deficiencies of Vitamin $\mathrm{C}$ and Zinc may represent a risk factor for post-herpetic neuralgia (41). Extrapolating 
further, there is limited evidence in experimentally induced neuropathic pain in animals, that changes to dietary intake particularly in relation to soy and omega fatty acids can help decrease neuropathic pain (12, 42-44). Soy contains flavonoids that have antioxidant and anti-inflammatory properties (27) and animal studies have shown genistein, a soy isoflavone, attenuates heat hyperalgesia associated with neuropathic pain (45).

A large proportion of the evidence cited in favour of nutrition's potential role in the pathophysiology of chronic OFP has been either based on in vitro findings, animal studies, or weak clinical evidence such as observational studies. Randomised controlled trials (RCTs) examining diet and nutritional interventions in chronic OFP can be interpreted as mechanistic trials that test the importance of nutrition in the aetiology of chronic OFP.

Given the potential for RCTs involving diet and nutritional interventions to be interpreted as mechanistic trials we examined the literature for such trials involving TMD, BMS, PDAP, and TN. Table 1 summarises the total number of

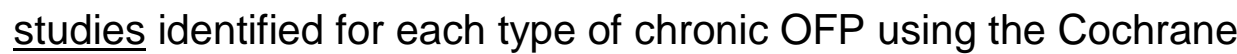
handbook's (46) "highly sensitive search strategy (sensitivity-maximizing version)" for RCTs involving TMD, BMS, PDAP, and or TN patients in MEDLINE (1966 to 7 July 2014 limited to English language and human studies, search strategy available upon request). The first author read the abstracts of all studies identified by the search strategy and proceeded to 
read the paper if the abstract indicated that a nutritional or dietary intervention was one of the arms of a RCT in either TMD, BMS, PDAP, or TN.

RCTs involving dietary or nutritional interventions were only found for Burning Mouth Syndrome (Table 1). Of the six RCTs identified, four involved alphalipoic acid (47-50), one involved Capsaicin (51), and one involved lycopene enriched virgin olive oil (52).

There was conflicting evidence for the role of alpha-lipoic acid in the management of burning mouth syndrome with two studies $(48,50)$ suggesting a reduction in pain, both in combination with, and without Gabapentin, and two other studies $(47,49)$ suggesting no effect for alpha-lipoic acid as a stand-alone therapy. All studies suffered from varying methodological flaws including: propensity for type II errors; quasi-randomisation; lack of follow-up and or intention-to-treat-analysis; inadequate blinding.

Lycopene-enriched virgin oil proved to perform no better than placebo when trialled (52) and Capsaicin proved to be better than placebo in reducing pain (51), however both the Lycopene and Capsaicin studies have significant methodological flaws similar to those affecting the alpha-lipoic acid studies. Given the scarcity of evidence and its somewhat contradictory and poorquality nature any role for nutrition in the pathophysiology of chronic OFP still, therefore, remains undetermined. 


\section{Potential role for nutrition in the management of chronic OFP}

The evidence base for the management of chronic OFP is generally of a poor quality and systematic reviews repeatedly call for new high-quality trials using homogenous samples and standardised patient-centred outcome measures (53). One area of consensus is the initial conservative reversible management of TMD (54) (55) which includes self-care and education alongside cognitive behavioural techniques. Most other chronic OFP conditions $(56,57)$ would also mandate self-care, education and cognitive behavioural techniques in one form or another. It is reasonable to suggest that optimising a patient's diet with reference to the limitations of their pain condition might be incorporated into this.

Attempting to optimise the patient's diet with reference to their (functional) limitations may help avoid otherwise anecdotal suggestions from clinicians: resting the jaw ("soft diet" in TMDs), or avoiding certain foods which are considered to exacerbate the condition. Advice such as this, if provided, is 'blind' to the possible impact that following such advice might have on nutritional status and longer-term health. The term "soft diet" is debatable at best and may be interpreted differently by patients and various health professionals. As previously indicated the aim is to reduce mandibular workload and as such any foods that may be cut, chopped or pureed would accomplish this independent of their initial texture. 
The major classes of systemic pharmacological agents used to manage chronic OFP include: antidepressants (serotonin norepinephrine re-uptake inhibitors, tricyclic antidepressants), anticonvulsants (Gabamimetics and Sodium channel blockers), analgesics (Paracetamol [acetaminophen], NSAIDs), and corticosteroids. All of these pharmacological agents can exert side effects relevant to diet and nutrition. These include: peptic ulceration, alteration in weight, and gastrointestinal disturbance including nausea or constipation. It is therefore important that management of the patient includes regular screening for these symptoms as they may lead to poor dietary choices.

Patients should be referred to a registered dietician if they are experiencing: difficulty eating an adequate and varied diet, weight change, or drug nutrient interactions. Without referral it is conceivable that such patients may become deficient in essential nutrients that may impact general health and well being.

Evaluation of patients' diet and nutritional status should be included in routine management of chronic OFP. Dietary advice to ensure that patients are consuming an adequate intake of energy, protein, and micronutrients to maintain general health and wellbeing is warranted. Such advice should include guidance on following national dietary guidelines for health promotion (e.g., http://www.nhs.uk/Livewell/healthy-eating/Pages/Healthyeating.aspx) 
and tailored to meet patients' individual needs and other comorbidities.

Recommendations on texture modification may be helpful for those with TMD. Such recommendations include peeling and chopping fresh fruits and vegetables and cutting and moistening meats, fish and poultry with marinades or natural juices. However, more research is required to ascertain the specific roles of different dietary components before more specialised treatmentspecific dietary advice becomes part of the everyday management of chronic OFP.

Simple approaches to nutritional and dietary assessment for non-dietetic health professionals exist:

- Screening techniques include: weighing patients and measuring their height in order to ascertain body mass index; inquiring about weight change over time; asking the patient to describe specific foods or fluids that they are limiting because of their chronic OFP; asking patients about use of special diets or dietary supplements and the rationale for these, and exploring any self-imposed dietary limitations; using the MUST tool (Malnutrition Universal Screening Tool (http://www.bapen.org.uk/screening-for-malnutrition/must/introducing$\underline{\text { must) }}$ to screen for malnutrition.

- Simple dietary assessment - asking patients about food group intake, listing items like fresh fruits, vegetables, protein-rich foods (meat, fish, poultry, nuts and beans, vegetable protein sources like tofu), dairy products and fats and sugar-rich foods and drinks and comparing their 
responses to national standards (e.g., Eatwell plate in UK and foodtracker.gov in USA). This simple assessment will provide some insight into unintentional weight change, dietary problems, diet quality, and can be used then to give the patient dietary guidance.

\section{Conclusion}

This commentary has highlighted the dearth of research assessing the various ways in which chronic OFP disorders, dietary intake, and nutrition may interact. Clearly there is some limited evidence for chronic OFP affecting dietary choice and thereby nutritional intake than for nutritional factors influencing pathophysiology of chronic OFP conditions. Given the strong drive to provide self-management techniques for chronic OFP conditions in the initial phases, it is somewhat surprising that more research has not been undertaken in relation to diet and nutrition. Evidence from other pain conditions suggests that an increased understanding of the role of nutrition in chronic OFP might help in an adjunctive capacity to improve outcomes of therapy. Specifically, early research needs to examine two broad areas: 1) the impact of chronic OFP conditions on dietary intake and nutritional status; 2) the impact of OFP on eating related quality of life. Once these areas have been examined in detail it may then be possible to identify, or rule out, any further research that may be required to examine the potential therapeutic role of specific dietary components in the management of OFP. 


\section{Bibliography}

1. Palacios C, Joshipura K, Willett W. Nutrition and health: guidelines for dental practitioners. Oral Dis 2009;15(6):369-381 .

2. Touger-Decker R, Mobley C. Position of the Academy of Nutrition and Dietetics: oral health and nutrition. J Acad Nutr Diet 2013;113(5):693-701.

3. Moynihan $\mathrm{P}$, Thomason $\mathrm{M}$, Walls $\mathrm{A}$ et al. Researching the impact of oral health on diet and nutritional status: methodological issues. J Dent 2009;37(4):237-249.

4. Hamdan NM, Gray-Donald K, Awad MA, Johnson-Down L, Wollin S, Feine JS. Do implant overdentures improve dietary intake? A randomized clinical trial. J Dent Res 2013;92(12 Suppl):146S-153S.

5. Morais JA, Heydecke G, Pawliuk J, Lund JP, Feine JS. The effects of mandibular two-implant overdentures on nutrition in elderly edentulous individuals. J Dent Res 2003;82(1):53-58.

6. Paillaud E, Merlier I, Dupeyron C, Scherman E, Poupon J, Bories PN. Oral candidiasis and nutritional deficiencies in elderly hospitalised patients. British Journal of Nutrition 2004;92(5):861-867.

7. Ritchie CS, Joshipura K, Silliman RA, Miller B, Douglas CW. Oral health problems and significant weight loss among community-dwelling older adults. J Gerontol A Biol Sci Med Sci 2000;55(7):M366-71.

8. al-Musaed AA, Zakrzewska JM, Bain BJ. Carbamazepine and folic acid in trigeminal neuralgia patients. J R Soc Med 1992;85(1):19-22. 
9. Irving J, Wood GD, Hackett AF. Does temporomandibular disorder pain dysfunction syndrome affect dietary intake? Dent Update 1999;26(9):405-407.

10. Loudon ME. "The importance of nutrition in TMJ treatment, periodontal treatment and dentistry". J Gen Orthod 1997;8(4):19-24.

11. Mallek $H$, Neff $P$, Nakamoto $T$. Interactions of nutrition and temporomandibular joint dysfunction. Ear Nose Throat $J$ $1984 ; 63(10): 499-504$.

12. Martin PR, MacLeod C. Behavioral management of headache triggers: Avoidance of triggers is an inadequate strategy. Clin Psychol Rev 2009;29(6):483-495.

13. Raphael KG, Marbach JJ, Touger-Decker R. Dietary fiber intake in patients with myofascial face pain. Journal of Orofacial Pain 2002;16(1):39-47.

14. Seltzer S, Dewart D, Pollack RL, Jackson E. The effects of dietary tryptophan on chronic maxillofacial pain and experimental pain tolerance. Journal of Psychiatric Research 1982;17(2):181-186.

15. Lipton J, Ship JA, Larach-Robinson D. Estimated prevalence and distribution of reported orofacial pain in the United States. Journal of the American Dental Association 1993;124(10):115-121.

16. IASP. International Association for the Study of Pain - Pain Terminology. 2007 
17. Reissmann DR, John MT, Schierz O, Wassell RW. Functional and psychosocial impact related to specific temporomandibular disorder diagnoses. J Dent 2007;35(8):643-650.

18. NICE. Clinical Knowledge summaries: Temporomandibular Joint Disorders. 2013

19. NIH. TMJ Disorders: how are TMJ disorders treated? 2013

20. Wright EF, Schiffman EL. Treatment alternatives for patients with masticatory myofascial pain. Journal of the American Dental Association 1995;126(7):1030-1039.

21. Nasri-Heir C, Benoliel R, Touger-Decker R, Epstein J, Eliav E. Orofacial Pain. In: Touger-Decker R, Mobley C, Epstein J, editors. Nutrition and Oral Medicine. New York: Springer; 2014. p. 313-332.

22. Ohrbach $\mathrm{R}$, Larsson $\mathrm{P}$, List $\mathrm{T}$. The jaw functional limitation scale: development, reliability, and validity of 8 -item and 20 -item versions. Journal of Orofacial Pain 2008;22(3):219-230.

23. Visscher CM, Ohrbach R, van Wijk AJ, Wilkosz M, Naeije M. The Tampa Scale for Kinesiophobia for Temporomandibular Disorders (TSK-TMD). Pain 2010;150(3):492-500.

24. Durham J, Steele J, Moufti MA, Wassell R, Robinson P, Exley C. Temporomandibular disorder patients' journey through care. Community Dent Oral Epidemiol 2011;39(6):532-541. 
25. Reissmann DR, John MT, Wassell RW, Hinz A. Psychosocial profiles of diagnostic subgroups of temporomandibular disorder patients. Eur J Oral Sci 2008;116(3):237-244.

26. Greene CS, Lerman MD, Sutcher HD, Laskin DM. The TMJ paindysfunction syndrome: heterogeneity of the patient population. Journal of the American Dental Association 1969;79(5):1168-1172.

27. Bell RF, Borzan J, Kalso E, Simonnet G. Food, pain, and drugs: does it matter what pain patients eat? Pain 2012;153(10):1993-1996.

28. Hertog MG, Feskens EJ, Hollman PC, Katan MB, Kromhout D. Dietary antioxidant flavonoids and risk of coronary heart disease: the Zutphen Elderly Study. Lancet 1993;342(8878):1007-1011.

29. Knekt P, Ritz J, Pereira MA et al. Antioxidant vitamins and coronary heart disease risk: a pooled analysis of 9 cohorts. Am J Clin Nutr 2004;80(6):1508-1520.

30. Lee FH, Raja SN. Complementary and alternative medicine in chronic pain. Pain 2011;152(1):28-30.

31. Rock CL, Jacob RA, Bowen PE. Update on the biological characteristics of the antioxidant micronutrients: vitamin $\mathrm{C}$, vitamin $\mathrm{E}$, and the carotenoids. J Am Diet Assoc 1996;96(7):693-702; quiz 703-4.

32. Thurnham DI. Carotenoids: functions and fallacies. Proceedings of the Nutrition Society 1994;53(1):77-87. 
33. Spencer JP, Vafeiadou K, Williams RJ, Vauzour D. Neuroinflammation: modulation by flavonoids and mechanisms of action. Molecular Aspects of Medicine 2012;33(1):83-97.

34. Waddington RJ, Moseley R, Embery G. Reactive oxygen species: a potential role in the pathogenesis of periodontal diseases. Oral Dis $2000 ; 6(3): 138-151$.

35. Zakrzewska JM, Forssell H, Glenny AM. Interventions for the treatment of burning mouth syndrome. Cochrane Database Syst Rev 2005(1):CD002779.

36. Buchanan J, Zakrzewska J. Burning mouth syndrome. Clin Evid 2002(7):1239-1243.

37. Buchanan J, Zakrzewska J. Burning mouth syndrome. Clin Evid 2003(9):1506-1511.

38. Buchanan J, Zakrzewska J. Burning mouth syndrome. Clin Evid 2004(11):1774-1780.

39. Koike $H$, lijima $M$, Sugiura $M$ et al. Alcoholic neuropathy is clinicopathologically distinct from thiamine-deficiency neuropathy. Annals of Neurology 2003;54(1):19-29.

40. Koike H, Sobue G. Alcoholic neuropathy. Current Opinion in Neurology 2006;19(5):481-486 . 
41. Chen JY, Chu CC, Lin YS, So EC, Shieh JP, Hu ML. Nutrient deficiencies as a risk factor in Taiwanese patients with postherpetic neuralgia. British Journal of Nutrition 2011;106(5):700-707.

42. Shir Y, Ratner A, Raja SN, Campbell JN, Seltzer Z. Neuropathic pain following partial nerve injury in rats is suppressed by dietary soy. Neuroscience Letters 1998;240(2):73-76.

43. Perez J, Ware MA, Chevalier S, Gougeon R, Shir Y. Dietary omega-3 fatty acids may be associated with increased neuropathic pain in nerveinjured rats. Anesth Analg 2005;101(2):444-8, table of contents.

44. Shir Y, Sheth R, Campbell JN, Raja SN, Seltzer Z. Soy-containing diet suppresses chronic neuropathic sensory disorders in rats. Anesth Analg 2001;92(4):1029-1034.

45. Valsecchi AE, Franchi S, Panerai AE, Rossi A, Sacerdote P, Colleoni M. The soy isoflavone genistein reverses oxidative and inflammatory state, neuropathic pain, neurotrophic and vasculature deficits in diabetes mouse model. European Journal of Pharmacology 2011;650(2-3):694702.

46. Lefebvre C, Manheimer E, Glanville J. Chapter 6: Searching for studies. In: Higgins JPT, Green S, editors. Cochrane Handbook for Systematic Reviews of Interventions Version 5.1.0 (updated March 2011). The Cochrane Collaboration; 2011. 
47. Carbone M, Pentenero M, Carrozzo M, Ippolito A, Gandolfo S. Lack of efficacy of alpha-lipoic acid in burning mouth syndrome: a double-blind, randomized, placebo-controlled study. Eur J Pain 2009;13(5):492-496.

48. Lopez-D'alessandro E, Escovich L. Combination of alpha lipoic acid and gabapentin, its efficacy in the treatment of Burning Mouth Syndrome: a randomized, double-blind, placebo controlled trial. Med Oral Patol Oral Cir Bucal 2011;16(5):e635-40.

49. Lopez-Jornet P, Camacho-Alonso F, Leon-Espinosa S. Efficacy of alpha lipoic acid in burning mouth syndrome: a randomized, placebo-treatment study. J Oral Rehabil 2009;36(1):52-57.

50. Femiano F, Scully C. Burning mouth syndrome (BMS): double blind controlled study of alpha-lipoic acid (thioctic acid) therapy. J Oral Pathol Med 2002;31(5):267-269.

51. Marino R, Torretta S, Capaccio P, Pignataro L, Spadari F. Different therapeutic strategies for burning mouth syndrome: preliminary data. $J$ Oral Pathol Med 2010;39(8):611-616.

52. Cano-Carrillo P, Pons-Fuster A, Lopez-Jornet P. Efficacy of lycopeneenriched virgin olive oil for treating burning mouth syndrome: a doubleblind randomised. J Oral Rehabil 2014;41(4):296-305.

53. Koh $\mathrm{H}$, Robinson PG. Occlusal adjustment for treating and preventing temporomandibular joint disorders. Cochrane Database Syst Rev 20031):CD003812. 
54. Greene CS. Managing the care of patients with temporomandibular disorders: a new guideline for care. Journal of the American Dental Association 2010;141(9):1086-1088.

55. Greene CS. The etiology of temporomandibular disorders: implications for treatment. Journal of Orofacial Pain 2001;15(2):93-105; discussion 106-16.

56. Aggarwal VR, Tickle M, Javidi $H$, Peters $S$. Reviewing the evidence: can cognitive behavioral therapy improve outcomes for patients with chronic orofacial pain? Journal of Orofacial Pain 2010;24(2):163-171.

57. Aggarwal VR, Lovell K, Peters S, Javidi H, Joughin A, Goldthorpe J. Psychosocial interventions for the management of chronic orofacial pain. Cochrane Database Syst Rev 2011(11):CD008456. 


\section{Disclosure/Acknowledgements}

The authors confirm they have no conflict of interest. This paper did not require ethical approval and was an unfunded piece of research. The authors thank the participants at the recent hands-on workshop on orofacial pain and nutrition led by the authors at IADR Seattle, 2013 for their enthusiasm towards starting some research in this area. 


\section{References}

Tables

Table 1 - Number of studies identified in literature for Burning mouth syndrome (BMS), Temporomandibular Disorders (TMD), Trigeminal Neuralgia (TN), and Persistent Dentoalveolar Pain Disorder (PDAP) using Cochrane Handbook's highly sensitive search strategy for Randomised Controlled Trials (46).

\begin{tabular}{|l|l|l|l|l|}
\hline Chronic orofacial pain condition & BMS & TMD & TN & PDAP \\
\hline $\begin{array}{l}\text { Total number of human and English language } \\
\text { studies identified from Medline (1966 to 7 July } \\
2014)\end{array}$ & 343 & 2700 & 1165 & 31 \\
\hline $\begin{array}{l}\text { Number of randomised controlled trials (RCT) } \\
\text { involving nutritional or dietary intervention in one } \\
\text { of the arms identified from total number of } \\
\text { studies }\end{array}$ & 6 & 0 & 0 & 0 \\
\hline
\end{tabular}


